\title{
The effect of early versus late treatment initiation after diagnosis on the outcomes of patients treated for multidrug-resistant tuberculosis: a systematic review
}

Rebecca C. Harris ${ }^{1 *}$, Louis Grandjean², Laura J. Martin³, Alexander J. P. Miller ${ }^{1}$, Joseph-Egre N. Nkang ${ }^{1}$, Victoria Allen ${ }^{4}$, Mishal S. Khan ${ }^{1,5}$, Katherine Fielding ${ }^{1,6}$ and David A. J. Moore ${ }^{1}$

\begin{abstract}
Background: Globally it is estimated that 480000 people developed multidrug-resistant tuberculosis (MDR-TB) in 2014 and 190000 people died from the disease. Successful treatment outcomes are achieved in only $50 \%$ of patients with MDR-TB, compared to $86 \%$ for drug susceptible disease. It is widely held that delay in time to initiation of treatment for MDR-TB is an important predictor of treatment outcome. The objective of this review was to assess the existing evidence on the outcomes of multidrug- and extensively drug-resistant tuberculosis patients treated early ( $\leq 4$ weeks) versus late ( $>4$ weeks) after diagnosis of drug resistance.

Methods: Eight sources providing access to 17 globally representative electronic health care databases, indexes, sources of evidence-based reviews and grey literature were searched using terms incorporating time to treatment and MDR-TB. Two-stage sifting in duplicate was employed to assess studies against pre-specified inclusion and exclusion criteria. Only those articles reporting WHO-defined treatment outcomes were considered for inclusion. Articles reporting on fewer than 10 patients, published before 1990, or without a comparison of outcomes in patient groups experiencing different delays to treatment initiation were excluded.

Results: The initial search yielded 1978 references, of which 1475 unique references remained after removal of duplicates and 28 articles published pre-1990. After title and abstract sifting, 64 papers underwent full text review. None of these articles fulfilled the criteria for inclusion in the review.

Conclusions: Whilst there is an inherent logic in the theory that treatment delay will lead to poorer treatment outcomes, no published evidence was identified in this systematic review to support this hypothesis. Reports of programmatic changes leading to reductions in treatment delay exist in the literature, but attribution of differences in outcomes specifically to treatment delay is confounded by other contemporaneous changes. Further primary research on this question is not considered a high priority use of limited resources, though where data are available, improved reporting of outcomes by time to treatment should be encouraged.
\end{abstract}

Keywords: Multi-drug resistant, Extensively drug resistant, Tuberculosis, Treatment delay, Systematic review

\footnotetext{
* Correspondence: rebecca.harris@lshtm.ac.uk

'TB Centre, London School of Hygiene and Tropical Medicine, Keppel Street,

London WC1E 7HT, UK

Full list of author information is available at the end of the article
}

\section{Biomed Central}

(c) 2016 Harris et al. Open Access This article is distributed under the terms of the Creative Commons Attribution 4.0 International License (http://creativecommons.org/licenses/by/4.0/), which permits unrestricted use, distribution, and reproduction in any medium, provided you give appropriate credit to the original author(s) and the source, provide a link to the Creative Commons license, and indicate if changes were made. The Creative Commons Public Domain Dedication waiver (http://creativecommons.org/publicdomain/zero/1.0/) applies to the data made available in this article, unless otherwise stated. 


\section{Background}

The widespread emergence of multidrug-resistant tuberculosis (MDR-TB) and extensively drug-resistant tuberculosis (XDR-TB) could limit the globally declining trend in tuberculosis (TB) prevalence that has been observed in recent years. It is estimated that worldwide $20 \%$ of previously treated TB cases and $3.3 \%$ of new TB cases now have multidrug-resistant tuberculosis - caused by bacterial strains resistant to at least isoniazid and rifampicin [1].

Treatment for MDR-TB and XDR-TB currently entails therapeutic regimens with much lower efficacy and greater toxicity than those used for drug-susceptible TB. Successful treatment outcome was only reported for $50 \%$ of MDR-TB patients globally in 2014, compared to $86 \%$ for newly diagnosed drug susceptible disease [1], and second line agents commonly used are poorly tolerated. Current recommendations for treatment of MDRTB require at least 20 months of therapy [2], though mounting evidence indicates that shorter regimens may perform at least as well [3].

Early treatment of MDR-TB is presumed to be associated with improved treatment outcomes, yet the evidence in support of this assumption has not been previously reviewed. Individuals with a prolonged delay to treatment are perceived as more likely to have a higher bacillary burden, more extensive lung damage and, as a result, active TB disease that is harder to treat. With the introduction of rapid diagnostic tools and reported reductions in time to identification and treatment of MDR-TB in many settings, there is interest in determining whether such reductions are associated downstream with improved MDR-TB treatment outcomes. Moreover some countries are struggling to keep up with the demand for MDR treatment as they diagnose more and more cases, creating "waiting lists" wherein patients have to wait until treatment capacity is available. Demonstration of an adverse effect upon patient outcome of such delays would be a potentially useful tool for strengthened advocacy to promote interventions that enhance linkage of test results to treatment.

We therefore undertook a systematic review of the existing evidence on the outcomes of multidrug-resistant and extensively drug-resistant tuberculosis patients treated early ( $\leq 4$ weeks) versus late $(>4$ weeks) after the diagnosis of drug resistance. This review contributes to the evidence base for the generation of an updated World Health Organization (WHO) guideline for the clinical management of MDR-TB and XDR-TB.

\section{Methods}

\section{PICOT Question}

The full original protocol and PRISMA checklist [4] (Additional file 1: Table S1) are available in the supporting information additional file section. The following amendments or clarifications were made to the original protocol: searching Google Scholar in place of Google, including a limit of publication since 1990, including a $10 \%$ check of sifting by a third reviewer, and allowing a flexible cut-off during sifting in the definition of the timing of early versus late treatment.

The research question was framed using PICOT (Population, Intervention, Comparison, Outcome and Time) methodology $[5,6]$. The population under consideration was all patients with multidrug-resistant or extensively drug-resistant tuberculosis bacteriologically confirmed by phenotypic methods, or for whom molecular testing indicating rifampicin resistance was used as a surrogate for initiation of MDR treatment. The intervention and comparator of interest were early versus late treatment, defined respectively as drug treatment initiated within 28 days versus later than 28 days after diagnosis of MDR-TB. The primary outcomes in this review were the WHO-defined tuberculosis outcomes as proposed by Laserson et al. [7]: cure, treatment completion, failure/ relapse, transfer out, abandoned treatment and death. Treatment success was defined as patients meeting the outcome definition of cure or treatment completed. Poor outcomes were defined as patients with the outcome of failure/relapse, transfer out, abandoned treatment or death. Secondary outcomes pre-defined in the protocol were not included in the search terms, but were intended for consideration during data extraction from included papers, and were defined as adverse reactions from TB drugs (severity, type, organ class), adherence to treatment, or treatment interruption due to non-adherence.

\section{Search strategy}

A comprehensive search strategy was developed in consultation with WHO technical experts using the PICOT question as a framework (see Additional file 1). Due to the relatively low number of total hits in preliminary searches, only population and intervention terms were used in the search strategy (Additional file 1: Table S2). By checking for comparator and outcomes defined a priori during the manual sift instead of in the search strategy, the likelihood of missing a potentially relevant paper was reduced. An example of the search strategy, in this case as applied in PubMed, is included in Additional file 1: Table S2.

Electronic health care databases, sources of evidencebased reviews, guidelines, and grey literature were searched in accordance with the specifications of each database. These included PubMed (including MEDLINE), EMBASE, Cochrane library (includes CENTRAL, CDSR, DARE and HTA databases), WHO Global Index Medicus (includes LILACS, WPRIM, IMSEAR, IMEMR, AIM, SciELO and WHOLIS indexes), WHO portal of clinical trials, OpenSIGLE, International Union of Tuberculosis and Lung Disease conference abstracts (2004-2014) and Google Scholar 
(limited to the first ten pages). The search strategies were executed on 26th September 2015. The date, human studies and language inclusion criteria were applied in the manual sifting process instead of through the limits function of PubMed (and other databases) in order to avoid exclusion of papers that had not been indexed on these criteria (Table 1).

\section{Manual sifting}

Following removal of duplicates, two-stage screening against inclusion and exclusion criteria was executed independently by two reviewers (JN, AM), sifting first by title and abstract, followed by full-text sifting. A third reviewer (DM) reviewed any discrepant results and every tenth reference to adjudicate and check for consistency. Studies including participants of any age with confirmed multi-drug resistant or extensively drug-resistant pulmonary tuberculosis were potentially eligible for inclusion. Any consecutive case series, case control study, cohort study, randomised controlled trial, systematic review or metaanalysis that included a comparator group was considered for inclusion. Included studies were required to report data on at least one of the primary outcome measures of interest. Although the original intervention of interest was defined as presumed adequate treatment initiated $\leq 28$ days after diagnosis, and a comparator group with treatment initiated $>28$ days after diagnosis, the protocol was changed to allow flexibility in the definition of this cut off for early versus late treatment. Therefore studies reporting outcomes for patient groups with different definitions for delay to treatment initiation were considered for inclusion.

Any systematic review superseded by an updated systematic review, or narrative reviews not adding new data or new analysis to the existing evidence base were excluded. Finally, studies not performed in humans, written in a language other than those listed in Table 1, or with fewer than ten participants were excluded.

Sifting was primarily managed within Endnote ${ }^{\circ}$ X7.4 (Thomson Reuters, California, USA). If a paper was

Table 1 Summary of non-PICO inclusion criteria

\begin{tabular}{lll}
\hline Limit category & Specified limit & Implementation \\
\hline Languages & $\begin{array}{l}\text { English, Japanese, Chinese, } \\
\text { Russian, French, Spanish, }\end{array}$ & Manual sifting \\
& Portuguese, Ukrainian, Lithuanian & \\
Publication type & None & n/a \\
Date of publication & 1st January 1990-26th Sept 2015 & Manual sifting \\
Study design & $\begin{array}{l}\text { Consecutive Case Series, Case } \\
\text { Control Studies, Cohort Studies, }\end{array}$ & Manual sifting \\
& $\begin{array}{l}\text { Randomised Controlled Trials, } \\
\text { Systematic Reviews }\end{array}$ & \\
& and Meta-analyses & n/a \\
\hline
\end{tabular}

deemed ineligible for inclusion at the full text sifting stage, the primary reason for ineligibility was recorded by the reviewers.

\section{Supplementary review and data extraction}

An additional post-hoc review of those articles included in the full text review was undertaken by one reviewer (DM) using alternative, less-stringent inclusion criteria. Specifically, papers were identified which reported on two or more groups of patients with different times to MDR treatment initiation. Data on treatment outcome according to WHO criteria or on intermediate outcomes such as culture conversion time (though not validated as surrogates of treatment outcome) were abstracted from papers included in this post-hoc review.

\section{Results}

A total of 1978 citations were retrieved from the initial search of all databases. Breakdown by database source is provided in Additional file 1: Table S3. After removal of duplicates $(n=475)$ and pre-1990 publications $(n=28)$, 1475 unique citations remained. 1411 hits were excluded during title and abstract screening. Sixty-four references were thus identified for full text review and all were retrieved [3, 8-70] (Fig. 1).

On full text review none of the 64 references fulfilled the per-protocol inclusion criteria. Reasons for exclusion are indicated in Fig. 1.

The most frequent reason for exclusion was the lack of a comparator group (91\% of full texts reviewed). Papers often reported average time to treatment, but did not disaggregate outcomes by timing of treatment, even with the more relaxed early versus late definition (not requiring a 28 day cut-off). Three narrative reviews were excluded as no new data were presented in addition to not meeting other inclusion/exclusion criteria for this review, two research articles were excluded as there were no reported outcomes of interest, and one reported on fewer than ten participants.

\section{Supplementary post-hoc review}

Although the full text review failed to deliver any publications fulfilling the inclusion criteria it was noted that a number of articles reported less well defined data on treatment delay (without a 28 day cut-off) related to some interim outcome measures (smear and culture conversion) and final treatment outcomes $[11,13,22,31,37,38,45$, $46,48,50,51,61,63,64,66,68]$.

None of these articles addressed the independent effect of treatment delay with a meaningful comparator group - whether not delayed or less delayed - upon treatment outcomes, whether interim or final.

Whilst outside the designated protocol we proceeded to abstract these data in case the resulting narrative 


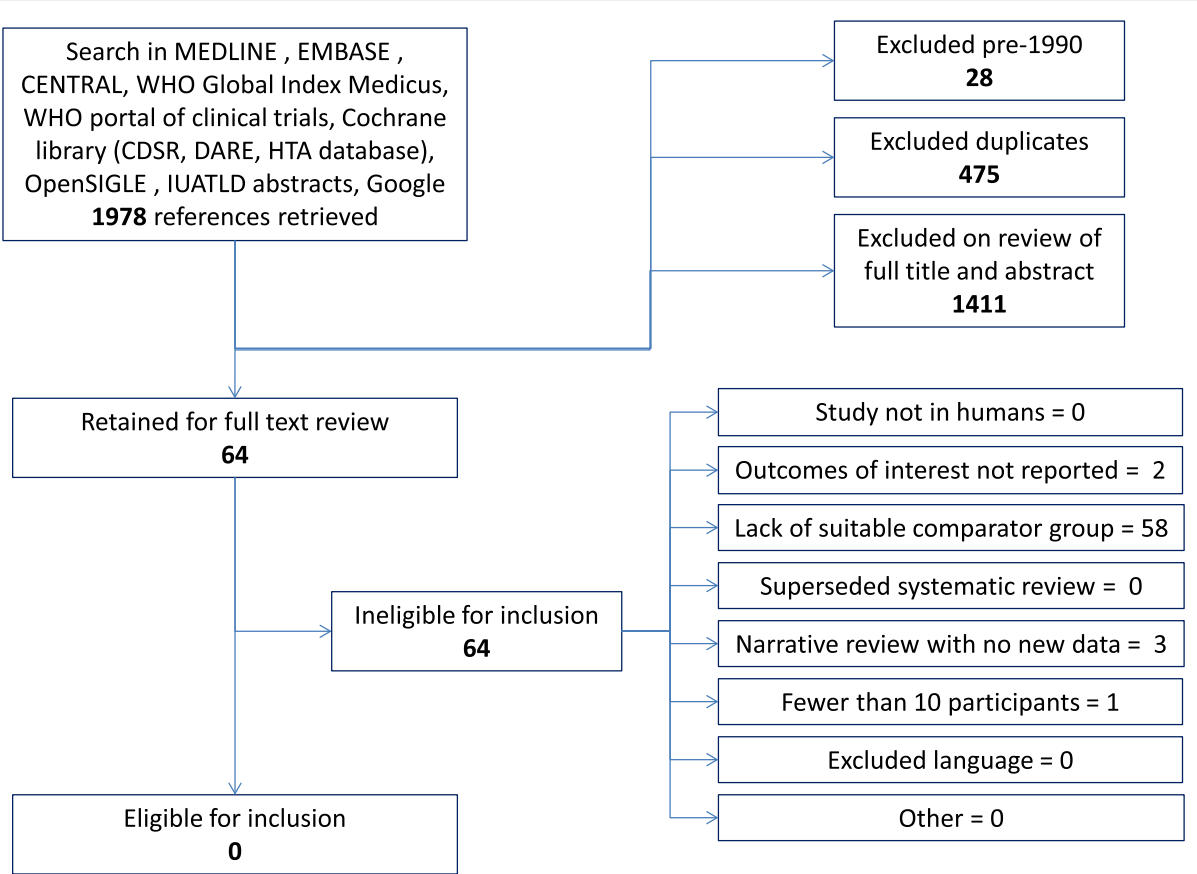

Fig. 1 Flow chart summarising search results

yielded any information of use. These data and narrative summary are reported in Table 2 and Additional file 1: supplementary text.

\section{Discussion}

Whilst there is an inherent logic in the theory that treatment delay will lead, via more severe disease, to worse treatment outcomes, we were unable to find any published evidence to support this assumption. More pertinently, there were no published data demonstrating an independent effect upon treatment outcome of earlier initiation of therapy following MDR diagnosis.

It is unfortunate that such data do not exist, as evidence highlighting a clear direct benefit upon patientcentred outcomes could have provided a powerful tool to advocate for specific interventions to improve linkage of MDR diagnosis to initiation of treatment, a particular problem for countries facing growing "waiting lists" of patients diagnosed with MDR-TB awaiting health system capacity to deliver treatment, or with considerable loss to follow up between testing and initiation of treatment. This systematic review found a lack of data rather than a lack of effect, therefore it should not be assumed that there is no benefit of early access to treatment. However, a recent systematic review evaluating the potential benefit of active case finding upon treatment outcomes for drug susceptible TB failed to demonstrate any improvement over passive case finding, despite the tendency of active case finding to find cases earlier and with reduced disease severity [71].
Regardless, beyond the effect for the individual, earlier treatment initiation should de facto result in reduced duration of infectiousness and thus result in reduced transmission at a community level. Treatment for MDRTB should clearly be initiated at the earliest opportunity after diagnosis.

A major obstacle in this review was the lack of suitable comparator group, as no studies reported treatment outcomes for otherwise similar patient groups varying only the time to treatment. Where outcome data were reported related to time to treatment, it was often confounded by simultaneous changes in other elements of healthcare delivery, such as programmatic changes related to delivery of care and altered drug regimens. Therefore, it was impossible to attribute differential outcomes to treatment delay.

The authors believe that further research with time to treatment as the primary research question should not be considered a high priority amongst competing demands upon limited resources. However, improved data collection and reporting of patient outcomes by time to treatment initiation should be encouraged in studies collecting data on the outcomes of interest in this patient group. Such data could provide important insight without cost implications.

Even if such data were available, treatment delay when defined as the interval from MDR diagnosis to treatment fails to take account of delays in reaching an MDR diagnosis, the effect of which might overwhelm any potential benefit of reduced diagnosis-to-treatment time. Roll-out of new rapid diagnostics, whether molecular tests such 
Table 2 Supplementary post-hoc review data

\begin{tabular}{|c|c|c|c|c|c|}
\hline Author & Journal & Year & Exposure & Outcome & Comments \\
\hline \multirow[t]{4}{*}{ Goble [38] } & \multirow[t]{4}{*}{ NEJM } & 1993 & Duration of disease & $\begin{array}{l}\text { Failure: continually positive sputum } \\
\text { cultures after at least three months } \\
\text { of therapy }\end{array}$ & \multirow[t]{4}{*}{ Duration of disease very long } \\
\hline & & & $1-3$ yrs & $12 / 44$ & \\
\hline & & & $4-8$ yrs & 18/44 OR $1.8(0.6-5.4)$ & \\
\hline & & & $\geq 9$ yrs & 17/46 OR $1.6(0.5-5.0)$ & \\
\hline Chan [37] & AJRCCM & 2004 & $\begin{array}{l}\text { Each additional year } \\
\text { delay before first visit to } \\
\text { site }\end{array}$ & $\begin{array}{l}\text { Initial favourable response: } \geq 3 \\
\text { negative sputum cultures over } \geq 3 \\
\text { months } \\
\text { OR } 0.93(0.87-0.995) p=0.03\end{array}$ & $\begin{array}{l}\text { Median pre-therapy disease duration = } \\
4.2 \text { years; analysis takes no account of } \\
\text { time to MDR therapy, just time to first } \\
\text { visit }\end{array}$ \\
\hline \multirow[t]{5}{*}{ Bonilla [66] } & \multirow[t]{5}{*}{ PLOS ONE } & \multirow[t]{5}{*}{2008} & & Treatment success & \multirow{5}{*}{$\begin{array}{l}\text { Paper mainly about individualisation of } \\
\text { regimens with DST and availability of } \\
2^{\text {nd }} \text { line DST within } 31 \text { days; no data on } \\
\text { lead-in time from diagnosis and } \\
\text { exclusions from primary analyses limit } \\
\text { interpretation }\end{array}$} \\
\hline & & & $\begin{array}{l}\text { MDR DST available } \\
\text { within } \leq 31 \text { days }\end{array}$ & 264/334 (79.0\%) & \\
\hline & & & $\begin{array}{l}\text { MDR DST available after } \\
>31 \text { days }\end{array}$ & $108 / 160(67.5 \%)$ & \\
\hline & & & $\begin{array}{l}\text { XDR DST available } \\
\text { within } \leq 31 \text { days }\end{array}$ & $11 / 14(78.6 \%)$ & \\
\hline & & & $\begin{array}{l}\text { XDR DST available after } \\
>31 \text { days }\end{array}$ & $7 / 23(30.4 \%)$ & \\
\hline \multirow[t]{5}{*}{ Dheda [31] } & \multirow[t]{5}{*}{ Lancet } & \multirow[t]{5}{*}{2010} & Treatment outcome & Delay to treatment & \multirow{5}{*}{$\begin{array}{l}\text { Compared delay to treatment in groups } \\
\text { of survivors and non-survivors and } \\
\text { culture converters and non-converters. } \\
\text { Delay to treatment = time from sputum } \\
\text { acquisition to start of treatment }\end{array}$} \\
\hline & & & Survival & 78 days [53-107] & \\
\hline & & & Death & $\begin{array}{l}57 \text { days }[36-67] \\
\mathrm{p}=0.001\end{array}$ & \\
\hline & & & Culture conversion & 91 days [61-116] & \\
\hline & & & Non-conversion & $\begin{array}{l}59 \text { days }[43-86] \\
\mathrm{p}=0.001\end{array}$ & \\
\hline \multirow[t]{12}{*}{ Heller [45] } & \multirow[t]{12}{*}{ IJTLD } & \multirow[t]{12}{*}{2010} & & $\begin{array}{l}\text { Median days }(95 \% \mathrm{Cl}) \text { treatment } \\
\text { delay }\end{array}$ & \multirow{12}{*}{$\begin{array}{l}\text { Before vs. after comparison following } \\
\text { change from traditional hospital based } \\
\text { management (TM) to community based } \\
\text { (CM). } \\
\text { In multivariate analysis time to smear } \\
\text { conversion was longer for TM group } \\
\text { than for CM group (aHR }=1.78, p=0.062 \text { ), } \\
\text { as was time to culture conversion } \\
\text { (aHR=1.82, } p=0.026 \text { ) }\end{array}$} \\
\hline & & & Traditional $(n=46)$ & $106.5(88.6-151.1)$ & \\
\hline & & & \multirow[t]{2}{*}{ Community (n=48) } & $84(78.7-93.3) p=0.002$ & \\
\hline & & & & $\begin{array}{l}\text { Median days }(95 \% \mathrm{Cl}) \text { to smear } \\
\text { conversion }\end{array}$ & \\
\hline & & & Traditional $(n=48)$ & $91(72.2-119.8)$ & \\
\hline & & & \multirow[t]{2}{*}{ Community (n=32) } & $59(34.9-83.1) p=0.055$ & \\
\hline & & & & $\begin{array}{l}\text { Median days }(95 \% \mathrm{Cl}) \text { to culture } \\
\text { conversion }\end{array}$ & \\
\hline & & & Traditional $(n=53)$ & $119(106.1-131.9)$ & \\
\hline & & & \multirow[t]{2}{*}{ Community (n=39) } & $\begin{array}{l}85(68.0-102.0) \\
p=0.002\end{array}$ & \\
\hline & & & & $\begin{array}{l}\text { Active and on treatment at } 6 \\
\text { months }\end{array}$ & \\
\hline & & & Traditional & $91.2 \%$ & \\
\hline & & & Community & $\begin{array}{l}84.8 \% \\
p=0.4\end{array}$ & \\
\hline Seddon [64] & $C I D$ & 2012 & $\begin{array}{l}\text { Treatment delay } \\
\text { (not defined) }\end{array}$ & $\begin{array}{l}\text { Not associated with: } \\
\text { [1] failure to culture convert by } \\
\text { month } 2 \\
(26 / 74, p=0.25) \\
\text { [2] unfavourable treatment } \\
\text { outcome } \\
(15 / 103, p=0.36) \\
{[3] \text { death }} \\
(8 / 103, p=0.18)\end{array}$ & $\begin{array}{l}\text { Median delay } 91 \text { days (IQR 51-166) } \\
\text { Data in table } 4 \text { - analysis not clear }\end{array}$ \\
\hline
\end{tabular}


Table 2 Supplementary post-hoc review data (Continued)

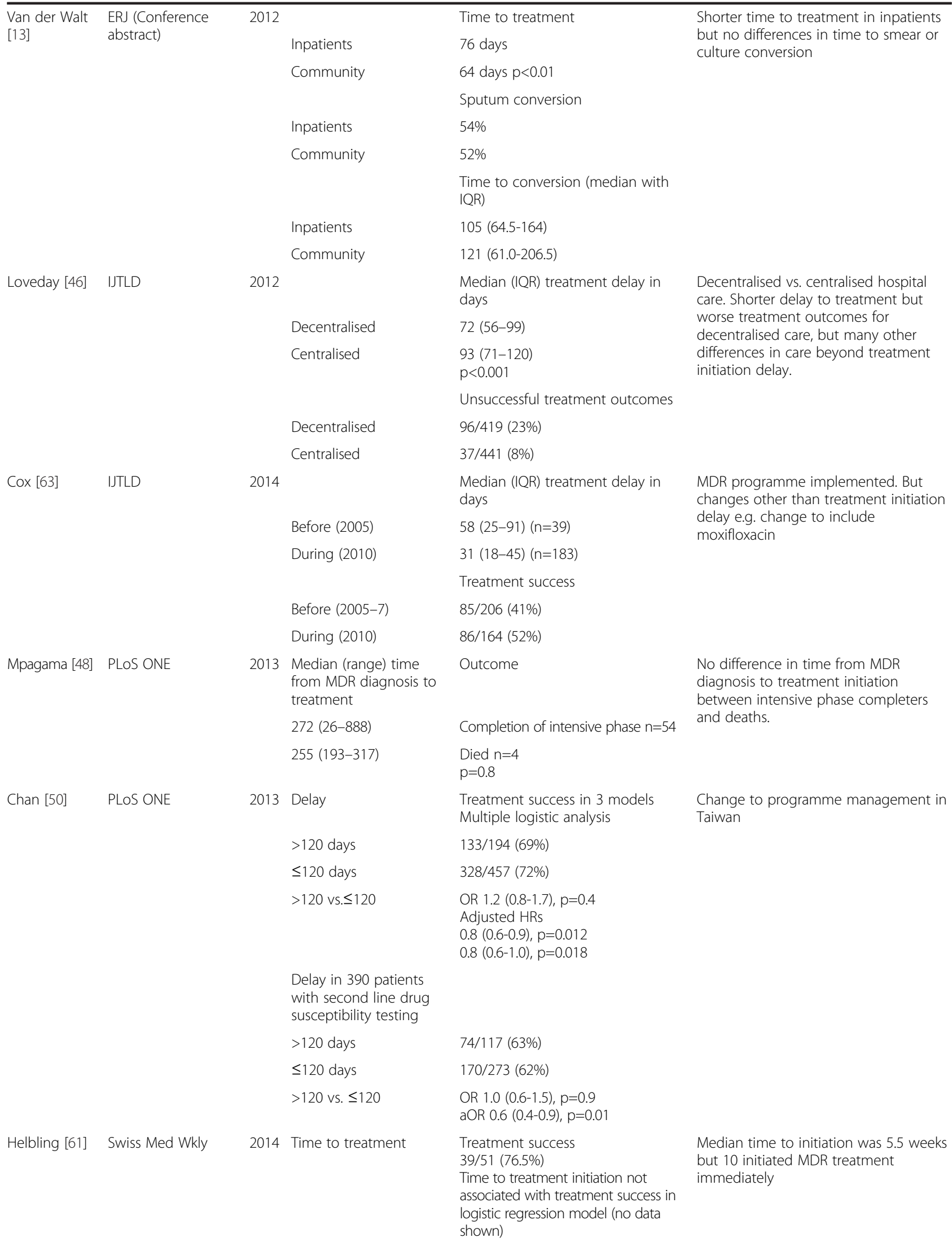


Table 2 Supplementary post-hoc review data (Continued)

\begin{tabular}{|c|c|c|c|c|c|}
\hline \multirow[t]{12}{*}{ Kipiani [68] } & \multirow[t]{12}{*}{$C I D$} & \multirow[t]{12}{*}{2014} & \multicolumn{2}{|l|}{$\begin{array}{l}\text { Line probe assay } \\
\text { implementation }\end{array}$} & \multirow{12}{*}{$\begin{array}{l}\text { Before vs. after analysis of line probe } \\
\text { assay implementation. Groups differed } \\
\text { in many ways - post implementation } \\
\text { group had more HCV co-infection, more } \\
\text { initial inpatient treatment, more likely to } \\
\text { receive kanamycin instead of } \\
\text { capreomycin, higher rates on prior MDR } \\
\text { treatment, resistant to more drugs. }\end{array}$} \\
\hline & & & Pre-implementation & $83.9(56-106)$ & \\
\hline & & & \multirow[t]{2}{*}{ Post-implementation } & $\begin{array}{l}18.2(11-24) p<0.01 \\
\text { (Unclear if overall or just for subset } \\
\text { who received first line drugs) }\end{array}$ & \\
\hline & & & & 12 wk culture conversion & \\
\hline & & & Pre-implementation & $5 / 68(7 \%)$ & \\
\hline & & & \multirow[t]{2}{*}{ Post-implementation } & 25/51 (49\%) & \\
\hline & & & & 24 week culture conversion & \\
\hline & & & Pre-implementation & $43 / 68(63 \%)$ & \\
\hline & & & \multirow[t]{2}{*}{ Post-implementation } & $\begin{array}{l}44 / 51(86 \%) \\
p=0.01\end{array}$ & \\
\hline & & & & 24 week smear conversion & \\
\hline & & & Pre-implementation & $77 \%$ & \\
\hline & & & Post-implementation & $\begin{array}{l}90 \% \\
p=0.05\end{array}$ & \\
\hline \multirow[t]{6}{*}{ Li [51] } & \multirow[t]{6}{*}{$\begin{array}{l}\text { Lancet Global } \\
\text { Health }\end{array}$} & \multirow[t]{6}{*}{2015} & $\begin{array}{l}\text { Programme } \\
\text { implementation }\end{array}$ & Median $[\mathrm{IQR}]$ time to treatment & \multirow{6}{*}{$\begin{array}{l}\text { Time to treatment only reported for } \\
32 \% \text { and } 71 \% \text { of pre- and post- } \\
\text { intervention patients }\end{array}$} \\
\hline & & & Before & 139 [69-207] & \\
\hline & & & \multirow[t]{2}{*}{ After } & $14[10-21]$ & \\
\hline & & & & Still on treatment at 6 months & \\
\hline & & & Before & $8 \%(2 / 26)$ & \\
\hline & & & After & $80 \%(137 / 172)$ & \\
\hline \multirow[t]{10}{*}{ Loveday [11] } & \multirow[t]{10}{*}{ IJTLD } & \multirow[t]{10}{*}{2015} & & $\begin{array}{l}\text { Median (IQR) treatment delay in } \\
\text { days }\end{array}$ & \multirow[t]{10}{*}{$\begin{array}{l}\text { Includes all of Loveday } 2012 \text { data plus } \\
\text { data for } 7 \text { additional months }\end{array}$} \\
\hline & & & Decentralised & $72(54-97)(n=724)$ & \\
\hline & & & Decentralised & $72(54-97)(n=724)$ & \\
\hline & & & \multirow[t]{2}{*}{ Centralised } & $\begin{array}{l}92(69-120)(n=811) \\
p<0.001\end{array}$ & \\
\hline & & & & Treatment success & \\
\hline & & & Decentralised & $427 / 736(58 \%)$ & \\
\hline & & & \multirow[t]{2}{*}{ Centralised } & $439 / 813(54 \%) p=0.18$ & \\
\hline & & & & Death & \\
\hline & & & Decentralised & 133/736 (18.1\%) & \\
\hline & & & Centralised & $113 / 813(13.9 \%) p=0.21$ & \\
\hline \multirow[t]{7}{*}{ Otero [22] } & \multirow[t]{7}{*}{ TMIH } & \multirow[t]{7}{*}{2015} & Treatment outcomes & $\begin{array}{l}\text { Median (IQR) time in days to MDR- } \\
\text { TB treatment }\end{array}$ & \multirow{7}{*}{$\begin{array}{l}\text { Should be noted that the duration of } \\
\text { treatment prior to switching was } \\
\text { undetermined. }\end{array}$} \\
\hline & & & $\begin{array}{l}\text { For patients starting on } \\
\text { MDR regimen: }\end{array}$ & & \\
\hline & & & Success & $26(18-41)$ & \\
\hline & & & Not success & $25(18-30) p=0.6$ & \\
\hline & & & $\begin{array}{l}\text { For patients switching } \\
\text { to MDR regimen: }\end{array}$ & & \\
\hline & & & Success & $11.5(2-35)$ & \\
\hline & & & Not success & $22(2-48) p=0.1$ & \\
\hline
\end{tabular}


as Xpert MTB/RIF or Genotype MTB DR-plus or direct phenotypic tests such as MODS or the nitrate reductase assay, is designed to reduce such delays through improved access and faster laboratory turnaround. Data comprehensively demonstrating an effect upon outcome of shortened time to MDR diagnosis are still awaited.

\section{Conclusion}

There is currently no published evidence available to assess the effect of early versus late treatment initiation upon the outcomes of patients treated for MDR-TB or XDR-TB. Whilst supportive evidence would have provided a useful advocacy tool, we feel that the intuitive logic and inherent biological plausibility mean that MDR treatment should be initiated promptly. Initiating primary research for this research question is not considered a priority amongst competing demands upon limited resources. However, improved collection of data on time to treatment initiation and treatment outcomes within other studies could provide insight into this question.

\section{Ethics approval and consent to participate}

Not Applicable.

\section{Availability of data and materials}

No data were identified for inclusion in the main review. The dataset supporting the post-hoc review in this article is included within the article in Table 2 and in the Additional file 1: supplementary text.

\section{Additional file}

Additional file 1: Table S1. PRISMA checklist. Table S2: Search terms applied in PubMed. Table S3: Number of search hits by database source. Supplementary post-hoc review text. (DOCX $139 \mathrm{~kb}$ )

\section{Abbreviations \\ MDR-TB: multidrug-resistant tuberculosis; PICOT: population, intervention, comparison, outcome and time; TB: tuberculosis; WHO: World Health Organization; XDR-TB: extensively drug resistant tuberculosis.}

\section{Competing interests}

RCH provides consultancy for GSK Vaccines on work unrelated to the topic of this review. All other authors report no potential competing interests.

\section{Authors' contributions}

Conceived and designed the protocol: RCH, LG, LM, DM, KF. Execution of search strategy: LG, LM. Sifting: JN, AM, DM, RCH. Manuscript preparation: $\mathrm{RCH}, \mathrm{DM}, \mathrm{VA}, \mathrm{KF}, \mathrm{LG}, \mathrm{MK}, \mathrm{LM}, \mathrm{JN}, \mathrm{AM}$. All authors read and approved the final manuscript.

\section{Acknowledgments}

We thank Dennis Falzon and Ernesto Jaramillo for the elaboration of the PICOT question.

\section{Funding}

This work was funded by the Global TB Programme of the World Health Organization and conducted to provide evidence for the 2015/16 revision of the WHO MDR-TB treatment guidelines.

\section{Author details}

'TB Centre, London School of Hygiene and Tropical Medicine, Keppel Street, London WC1E 7HT, UK. ${ }^{2}$ Department of Infection, Immunology and Rheumatology, University College London, Institute of Child Health, Guilford Street, London WC1E 6BT, UK. ${ }^{3}$ Royal Brompton and Harefield NHS Foundation Trust, Sydney Street, London SW3 6NP, UK. ${ }^{4}$ Chelsea and Westminster Hospital, 369 Fulham Road, London SW10 9NH, UK. ${ }^{5}$ Saw Swee Hock School of Public Health, National University of Singapore, Singapore 119077, Singapore. ${ }^{6}$ The School of Public Health, University of the Witwatersrand, Johannesburg, South Africa.

Received: 23 March 2016 Accepted: 22 April 2016

Published online: 04 May 2016

\section{References}

1. Global Tuberculosis Report 2015. Geneva: World Health Organisation; 2015.

2. Guidelines for the programmatic management of drug-resistant tuberculosis. Geneva: World Health Organisation; 2011.

3. Van Deun A et al. Short, highly effective, and inexpensive standardized treatment of multidrug-resistant tuberculosis. Am J Respir Crit Care Med. 2010;182(5):684-92.

4. Moher $\mathrm{D}$ et al. Preferred reporting items for systematic reviews and metaanalyses: the PRISMA statement. Ann Intern Med. 2009;151(4):264-9. w64.

5. Richardson WS et al. The well-built clinical question: a key to evidence-based decisions. ACP J Club. 1995;123(3):A12-3.

6. Haynes RBSDL, Guyatt GH, Tugwell PS. Clinical epidemiology: how to do clinical practice research. 3rd ed. Philadelphia: Lippincott Williams \& Wilkins; 2006.

7. Laserson KF, et al. Speaking the same language: treatment outcome definitions for multidrug-resistant tuberculosis. Int J Tuberc Lung Dis. 2005;9(6):640-5.

8. Yu MC, et al. Characteristics and treatment outcomes of MDR tuberculosis in Taiwan. Int J Infect Dis. 2014;21 (Supplement 1):57.

9. Mukherjee JS, et al. Clinical and programmatic considerations in the treatment of MDR-TB in children: a series of 16 patients from lima, Peru. Int J Tuberc Lung Dis. 2003;7(7):637-44.

10. Javia A, et al. Clinical profile of MDR-TB patients and their early response to DOTS PLUS: An Indian perspective. Eur Respir J. 2013;42(Suppl 57).

11. Loveday M, et al. Community-based care vs. Centralised hospitalisation for MDRTB patients, KwaZulu-Natal, South Africa. Int J Tuberc Lung Dis. 2015:9(2):163-71.

12. Ganzaya S, et al. Countrywide audit of multidrug-resistant tuberculosis and treatment outcomes in Mongolia. Public Health Action. 2013;3(4):333-6.

13. Van Der Walt $\mathrm{M}$, et al. Culture conversion rates of multidrug resistant (MDRTB) patients treated in the community versus an inpatient setting in a rural area of the Western Cape (WC) of South Africa. Eur Respir J. 2012; 40(Suppl 56).

14. Garcia-Garcia Ma DL, et al. Drug resistance of Mycobacterium tuberculosis in Orizaba, Veracruz. Implications for the tuberculosis prevention and control program. Rev Investig Clin. 2001;53(4):315-23.

15. Dave $\mathrm{P}$, et al. Has introduction of rapid drug susceptibility testing at diagnosis impacted treatment outcomes among previously treated tuberculosis patients in Gujarat, India? PLoS One. 2015;10(4):e0121996.

16. Ahmad N, et al. Management and treatment outcomes of MDR-TB: Results froma setting with high rates of drug resistance. Int J Tuberc Lung Dis. 2015;19(9):1109-14.

17. Mukherjee JS, et al. New challenges in the clinical management of drug-resistant tuberculosis. Infect Dis Clin Pract. 2002;11(6):329-339.

18. Satti $\mathrm{H}$, et al. Outcomes of multidrug-resistant tuberculosis treatment with early initiation of antiretroviral therapy for HIV co-infected patients in Lesotho. PLoS One. 2012;7(10):e46943.

19. Handayani $\mathrm{D}$, et al. Profile and treatment outcome of extensive drug resistant tuberculosis (XDR-TB) patients in Persahabatan Hospital, Jakarta Indonesia. Respirology. 2013;18: 3-4. doi: 10.1111/resp.12183_2.

20. Drobniewski FA, Balabanova YM. The diagnosis and management of multiple-drug-resistant tuberculosis at the beginning of the new millenium. Int J Infect Dis. 2002;6(1):S21-31.

21. Migliori GB, et al. The XDR-TB emergency: Answers from the scientific community. Rassegna di Patologia dell'Apparato Respiratorio. 2009;24(5): 319-24.

22. Otero $L$, et al. Time to initiation of multidrug-resistant tuberculosis treatment and its relation with outcome in a high incidence district in Lima, Peru. Trop Med Int Health. 2015;20(3):322-5. 
23. Milanov $V$, et al. Treatment outcome and factors associated with unfavourable treatment results in cases with multidrug-resistant tuberculosis in Bulgaria for the period 2009-2010. Eur Respir J. 2012;4(2):131-7.

24. Doh HK, et al. Treatment outcomes and long-term survival in patients with extensively drug-resistant tuberculosis. Am J Respir Crit Care Med. 2008; 178(10):1075-82.

25. Park J, et al. Treatment outcomes and prognostic factors in Korean patients with multidrug resistant tuberculosis. Respirology. 2009;14:A170-A295. doi: 10.1111/j.1440-1843.2009.01658.x

26. Isaakidis P, et al. Treatment outcomes for HIV and MDR-TB co-infected adults and children: systematic review and meta-analysis. Int J Tuberc Lung Dis. 2015;19(8):969-78.

27. Marks SM, et al. Treatment practices, outcomes, and costs of multidrugresistant and extensively drug-resistant tuberculosis, United States, 2005-2007. Emerg Infect Dis. 2014;20(5):812-21.

28. Leimane $V$, et al. Clinical outcome of individualised treatment of multidrug-resistant tuberculosis in Latvia: a retrospective cohort study. Lancet. 2005;365(9456):318-26.

29. Mitnick C, et al. Community-based therapy for multidrug-resistant tuberculosis in Lima. Peru N Engl J Med. 2003;348(2):119-28.

30. Schaaf HS, Shean K, Donald PR. Culture confirmed multidrug resistant tuberculosis: diagnostic delay, clinical features, and outcome. Arch Dis Child. 2003;88(12):1106-11.

31. Dheda K, et al. Early treatment outcomes and HIV status of patients with extensively drug-resistant tuberculosis in South Africa: a retrospective cohort study. Lancet. 2010;375(9728):1798-807.

32. Kim H-R, et al. Impact of extensive drug resistance on treatment outcomes in non-HIV-infected patients with multidrug-resistant tuberculosis. Clin Infect Dis. 2007;45(10):1290-5.

33. Geerligs WA, et al. Multidrug-resistant tuberculosis: long-term treatment outcome in the Netherlands. Int J Tuberc Lung Dis. 2000;4(8):758-64.

34. Park SK, Kim CT, Song SD. Outcome of chemotherapy in 107 patients with pulmonary tuberculosis resistant to isoniazid and rifampin. Int J Tuberc Lung Dis. 1998;2(11):877-84.

35. Flament-Saillour M, et al. Outcome of multi-drug-resistant tuberculosis in France: a nationwide case-control study. Am J Respir Crit Care Med. 1999;160(2):587-93.

36. Keshavjee $\mathrm{S}$, et al. Treating multidrug-resistant tuberculosis in Tomsk, Russia. Ann N Y Acad Sci. 2008;1136(1):1-11.

37. Chan ED, et al. Treatment and outcome analysis of 205 patients with multidrugresistant tuberculosis. Am J Respir Crit Care Med. 2004;169(10):1103-9.

38. Goble M, et al. Treatment of 171 patients with pulmonary tuberculosis resistant to isoniazid and rifampin. N Engl J Med. 1993;328(8):527-32.

39. Keshavjee $\mathrm{S}$, et al. Treatment of extensively drug-resistant tuberculosis in Tomsk, Russia: a retrospective cohort study. Lancet. 2008;372(9647):1403-9.

40. Wood AJJ, Iseman MD. Treatment of multidrug-resistant tuberculosis. N Engl J Med. 1993;329(11):784-91.

41. Leimane $V$, et al. Treatment outcome of multidrug/extensively drug-resistant tuberculosis in Latvia, 2000-2004. Eur Respir J. 2010;36(3):584-93.

42. Ettehad D, et al. Treatment outcomes for children with multidrug-resistant tuberculosis: a systematic review and meta-analysis. Lancet Infect Dis. 2012; 12(6):449-56.

43. Orenstein EW, et al. Treatment outcomes among patients with multidrugresistant tuberculosis: systematic review and meta-analysis. Lancet Infect Dis. 2009;9(3):153-61.

44. Kwon YS, et al. Treatment outcomes for HIV-uninfected patients with multidrug-resistant and extensively drug-resistant tuberculosis. Clin Infect Dis. 2008;47(4):496-502.

45. Heller T, et al. Community-based treatment for multidrug-resistant tuberculosis in rural KwaZulu-Natal, South Africa. Int J Tuberc Lung Dis. 2010;14(4):420-6.

46. Loveday $\mathrm{M}$, et al. Comparing early treatment outcomes of MDR-TB in decentralised and centralised settings in KwaZulu-Natal, South Africa. Int J Tuberc Lung Dis. 2012;16(2):209-15.

47. Shin SS, et al. Development of extensively drug-resistant tuberculosis during multidrug-resistant tuberculosis treatment. Am J Respir Crit Care Med. 2010;182(3):426-32.

48. Mpagama SG, et al. Diagnosis and interim treatment outcomes from the first cohort of multidrug-resistant tuberculosis patients in Tanzania. PLoS One. 2013;8(5):e62034

49. Zhang $X$ et al. Diagnostic and treatment delays of multidrug-resistant tuberculosis before initiating treatment: a cross-sectional study. Tropical Med Int Health. 2015;20(11):1431-7.
50. Chan P-C, et al. Effectiveness of a government-organized and hospitalinitiated treatment for multidrug-resistant tuberculosis patients-a retrospective cohort study. PLoS One. 2013;8(2):e57719.

51. Li R, et al. Effect of a comprehensive programme to provide universal access to care for sputum-smear-positive multidrug-resistant tuberculosis in China: a before-and-after study. Lancet Global Health. 2015;3(4):e217-28.

52. Seddon JA, et al. High treatment success in children treated for multidrugresistant tuberculosis: an observational cohort study. Thorax. 2014;69(5):458-64.

53. Gandhi NR, et al. HIV coinfection in multidrug-and extensively drug-resistant tuberculosis results in high early mortality. Am J Respir Crit Care Med. 2010;181(1):80-6.

54. Velásquez $\mathrm{GE}$, et al. Improving outcomes for multidrug-resistant tuberculosis: aggressive regimens prevent treatment failure and death. Clin Infect Dis. 2014;59(1):9-15.

55. Gegia M, et al. Outcomes of children treated for tuberculosis with second-line medications in Georgia, 2009-2011. Int J Tuberc Lung Dis. 2013;17(5):624-9.

56. Schnippel $K$, et al. Predictors of mortality and treatment success during treatment for rifampicin-resistant tuberculosis within the South African National TB Programme, 2009 to 2011: a cohort analysis of the national case register. Int J Infect Dis. 2015;39:89-94.

57. Mohr E, et al. Programmatic treatment outcomes in HIV-infected and uninfected drug-resistant TB patients in Khayelitsha, South Africa. Trans R Soc Trop Med Hyg. 2015;109(7):425-32.

58. Mirsaeidi SM, et al. Treatment of multiple drug-resistant tuberculosis (MDR-TB) in Iran. Int J Infect Dis. 2005;9(6):317-22.

59. Jeon DS, et al. Treatment outcome and mortality among patients with multidrug-resistant tuberculosis in tuberculosis hospitals of the public sector. J Korean Med Sci. 2011;26(1):33-41.

60. Charles M, et al. Treatment outcomes for patients with multidrug-resistant tuberculosis in post-earthquake Port-au-Prince, Haiti. AmJTrop Med Hyg. 2014:91(4):715-21.

61. Helbling $P$, et al. Treatment outcomes of multidrug-resistant tuberculosis in Switzerland. Swiss Med Wkly. 2014;144:w14053.

62. Drobac PC, et al. Community-based therapy for children with multidrugresistant tuberculosis. Pediatrics. 2006;117(6):2022-9.

63. Cox H, et al. Community-based treatment of drug-resistant tuberculosis in Khayelitsha, South Africa. Int J Tuberc Lung Dis. 2014;18(4):441-8.

64. Seddon JA, et al. Culture-confirmed multidrug-resistant tuberculosis in children: clinical features, treatment, and outcome. Clin Infect Dis. 2012;54(2):157-66.

65. Piubello A, et al. High cure rate with standardised short-course multidrugresistant tuberculosis treatment in Niger: no relapses. Int J Tuberc Lung Dis. 2014;18(10):1188-94.

66. Bonilla CA, et al. Management of extensively drug-resistant tuberculosis in Peru: cure is possible. PLoS One. 2008;3(8):e2957.

67. Singla R, et al. Seven-year DOTS-Plus pilot experience in India: results, constraints and issues. Int J Tuberc Lung Dis. 2009;13(8):976-81.

68. Kipiani M, et al. Significant clinical impact of a rapid molecular diagnostic test (Genotype MTBDRplus assay) to detect multidrug-resistant tuberculosis. Clin Infect Dis. 2014;59(11):1559-66.

69. Holtz TH, et al. Time to sputum culture conversion in multidrug-resistant tuberculosis: predictors and relationship to treatment outcome. Ann Intern Med. 2006;144(9):650-9.

70. Park JK, et al. Treatment outcomes and prognostic factors in patients with multidrug-resistant tuberculosis in Korean private hospitals. Tuberc Respir Dis. 2010:69(2):95-102.

71. Kranzer $K$, et al. The benefits to communities and individuals of screening for active tuberculosis disease: a systematic review. Int J Tuberc Lung Dis. 2013;17(4):432-46 